\title{
The effects of community participation program on smoke- free homes in a suburban community of Thailand
}

\author{
Peeraya Suteerangkul', Sunee Lagampan², Surintorn Kalampakorn², Naruemon Auemaneekul
}

\begin{abstract}
INTRODUCTION Smoking inside the home affects the health of both the smoker and family members via secondhand exposure. This research examined the impact of a community participation program on creating smoke-free homes in a suburban community in Thanyaburi district, Pathumthani province in Thailand.

METHODS The study involved families, with a smoker in the home, that were randomly assigned to intervention and control groups each containing 27 families. The intervention group was administered with the community participation program for smoke-free homes for 5 sessions during the 6-month period of study. The program included providing information on secondhand smoking and harms, knowledge about quitting smoking and healthcare support, practice skills, campaigns in the community, visiting and encouraging, and reflecting and evaluation. The control group was normally treated by the community committee and health volunteers. Data collection was undertaken at baseline and at 6 months after implementation by an interview with questionnaires.

RESULTS Our results show that after the implementation, the intervention group reported significantly higher mean score on skills in negotiating with smokers for a smoking-ban inside home and mean score on emotional support for nonsmoking inside the home than those at baseline and those of the control group. The proportion having smoking ban home rules in the intervention group was significantly higher than at baseline and that of the control group $(92.6 \%$ vs $18.5 \%)$. The proportion of smoke-free homes was higher in the intervention than in the control group ( $75 \%$ vs $0 \%$ ).

conclusions These findings suggest that community participation programs for smoke-free home may be effective in raising awareness on the impact of secondhand smoke among family members and in working together to manage smoke-free home environments. The program may be applicable for further development within communities to achieve smoke-free homes.
\end{abstract}

AFFILIATION
1 School of Nursing, Eastern
Asia University, Pathumthani,
Thailand
2 Department of Public
Health Nursing, Faculty
of Public Health, Mahidol
University, Bangkok, Thailand
CORRESPONDENCE TO
Sunee Lagampan. Department
of Public Health Nursing,
Faculty of Public Health,
Mahidol University, Bangkok,
Thailand. E-mail: sunee.lag@
mahidol.ac.th
KEYwORDS
community participation,
smoke-free home, negotiation
skills, smoking ban, emotional
support

Received: 21 September 2020 Revised: 2 March 2021 Accepted: 2 March 2021

\section{INTRODUCTION}

Secondhand smoke (SHS) is a major public health problem $^{1}$ and commonly noted at home ${ }^{2,3}$. Exposure to secondhand smoke is significantly associated with the prevalence of hypertension, angina, and stroke $e^{4}$. In the US, economic costs attributable to smoking and exposure to secondhand smoke now approach $\$ 300$ billion annually ${ }^{5}$. Regulating smoking inside households is challenging since the home is a private place 6 . Recent research has also reported that no smoking inside the home was associated with education level, particularly among higher educated adults $^{7}$. Populations may be unaware of the dangers of secondhand smoke ${ }^{8}$. Smoking has become a misleading value that passes on from smoking parents to the youth in the home'. 
In Thailand, the Royal Thai government had enacted the Tobacco Control Act, combined with the Health Care Act for non-smokers, but the target was not reached as cigarette consumption was not affected by a tax increase ${ }^{10}$. A previous study showed the prevalence of smokers among Thai adults was $45.6 \%$ for men and $3.1 \%$ for women ${ }^{11}$. Even if additional tobacco control measures have successfully reduced smoking in public areas, SHS exposure at home is still a public health problem as the legislation could not cover personal areas. Additionally, it was not clear if a law prohibiting secondhand smoke exposure at home would come into effect in $2020^{12}$.

To improve the indoor air environment, smoking bans in the entire household should be implemented ${ }^{13-15}$. The primary issue is that smokers may be unable to quit smoking ${ }^{16}$. The solution often focuses on particular groups, and previous research results usually emphasized only increasing awareness ${ }^{16}$. Within family interventions, family members may have failed to participate and have lacked the negotiation skills to support smokers' behavioral change, especially regarding a smoker who may be the household head. Negotiation skills are essential to solving problems in human life ${ }^{17}$. Effective tobacco control programs should therefore include a focus at the level of the community, helping community leaders and family members to promote their skills in negotiating ${ }^{6}$ with smokers, campaigns for smoke-free home environments, and community participation, so as to strive for sustainable community development. Exposure to secondhand smoke inside the home is an urgent issue to be resolved and requires the collaboration of all sectors including local agencies, community committees and family members, as well as smokers who need to cooperate with the community.

Aligning with the objectives of Healthy People $2020^{18}$ to reduce the problem of secondhand smoke and increase the number of smoke-free homes, this research aimed at examining the effects of a community participation program on implementing smoke free-homes within a suburban community in the Thanyaburi district of the Pathumthani province in Thailand.

\section{METHODS}

\section{Design and setting}

This study had a quasi-experimental research design using a two-group pretest-posttest design. The population included families of smokers who resided in the respective area of the Thanyaburi district of the Pathumthani province ${ }^{19}$.

\section{Participants}

Participants were recruited by: 1) purposive sampling from 1 community in each of the 2 subdistricts with similar characteristics under the local administration of Thanyaburi municipality (two communities had strong community leaders and supported program implementation until end of the program); 2) simple random sampling, with one community as a control group and another as intervention group (lottery sampling); and 3) randomly selected families with a smoker in the home to obtain intervention families and control families. The sample size was calculated by $\mathrm{G}^{*}$ Power analysis based on the effect size of 0.80 , $Z_{a}=1.96$ (value of error $a$ of 0.05 ), $\beta=0.20$, and power of the test $(1-\beta)=0.80$, which led to a sample size of 26 in each group. To take into account potential sample loss, the sample size was increased by $15 \%$ to 30 persons in each group.

We advertised to each community for families that met the inclusion criteria and voluntarily could participate in the research. The inclusion criteria were: families residing for at least 6 months in the community and having family members living with a smoker in the same home (father, mother, child or relative), aged $\geq 18$ years, with no history of narcotics use, or having severe stage chronic disease or neuropsychological disorders. Exclusion criteria were: participants who refused to give information and did not wish to join the study, who moved to another community, or had an accident or serious health problem.

Clarification was made to the participants about their participation and they were asked to sign a consent form to voluntarily participate in the program. Participants were free to withdraw from the program at any time. At the end of the program at 6 months, 27 families remained in the intervention group because two families moved out of the area to other provinces, and in one family the smoker had died. In the control group, 27 families also remained as three families moved out of the area to other provinces.

Two research instruments were employed, a program developed by the community committee 
based on participation in the Community Participation Program for a Smoke-Free Home (Supplementary file Table S1), and a data collection instrument. Other materials and media used for the program were a Smoke-free Home Kit, which contained smokefree home pamphlets and tobacco-related illness brochures, Pico Smokerlyzer ${ }^{\circledR}$, digital blood pressure equipment, and a handbook. Storyboards were created by a community volunteer and researcher on the topic of 'Tobacco Danger' and showed to the community.

\section{Data collection instruments}

Data collection involved a questionnaire on general characteristics of the family including sex, age, education level, family status, congenital disease, family relationships, and presence of smoking-ban home rule/regulation. Structured interview form was constructed by the researcher and consisted of the following parts:

Part 1: Negotiation with the smoker, measured by 10 items on four-rating scales. These involved asking family members about their behaviors related to listening to the current smokers and behavior towards the current smokers, explaining the objective, giving reasons and choices for setting up smoking ban rules together, and keeping good relationships within the family. The total score was 40 with each item scored as follows: regular practice $=4$, often practice $=3$, sometimes practice $=2$, rarely practice $=1$, and the negative statements were reversed. The reliability of rating scales was analyzed and Cronbach's alpha coefficient $=0.89$. Content validity index of negotiation for a smoking ban at home was 0.79 .

Part 2: Emotional support for no smoking inside home, measured by 6 items on four-rating scales. These involved asking family members about their caring support, listening to smokers, helping, doing activities together, encouraging and appreciating smoking cessation inside the home, being concerned and giving love. The total score was 24 , each item was scored as follows: regular practice $=4$, often practice $=3$, sometimes practice $=2$, rarely practice $=1$ and the negative statements were reversed. The reliability of rating scales was analyzed and Cronbach's alpha coefficient $=0.93$. Content validity index of negotiation for a smoking ban at home was 0.73 .

Smoke-free homes were assessed by two questions: 1) 'Is there a total ban on smoking inside the home?', and 2) 'Is there anyone smoking inside the home or outside at fence?'. Responses were 'yes' or 'no'.

\section{Data collection}

The research was conducted from December 2016 to June 2017. The intervention group that followed the Community Participation Program for Smoke-Free Homes involved the five sessions (Supplementary file Table S1). The control group was normally handled by the community committee and health promotion volunteers and included the provision of advice on sources of service for smoking cessation and a campaign for a smoke-free home. At the end of the program (at 6 months), the research team educated the control group on smoke-free homes and the hazards of secondhand smoke and gave out a handbook on smoke-free homes and the dangers of tobacco in developing various chronic diseases. This research was approved by the Ethical Review Committee for Human Research, Faculty of Public Health, Mahidol University (COA. No. MUPH 2016-114). Data were collected by research participants conducted by the researcher and research assistants at two-time points at baseline, prior to project implementation at week one and after implementation at week 24 .

\section{Statistical analysis}

Descriptive statistics was used to calculate frequency, percentage, mean, and standard deviation. Chisquared test was used to compare the distribution of background between groups. Paired t-test was used to determine the difference of mean score within group before and after project implementation. Test of the difference in mean scores between intervention and control groups was performed with independence t-test. Test of the difference in proportion of the presence of smoking-ban home rule and proportion of smoke-free home and dichotomous variables used Fisher's exact test. A significance level for test of hypothesis was determined at 0.05 .

\section{RESULTS}

\section{General characteristics}

Both sample groups were similar in characteristics with an age between 18 and 86 years (intervention group: mean age $=49.9 \pm 18.8$; control group: mean age $=51.9 \pm 19.7)$. Most of the family members were female $(81.5 \%$ in the intervention group; $85.2 \%$ in the 
control group); attained primary education (51.9\% in the intervention group; $55.6 \%$ in the control group). Family members ranged 2-7 persons. The age of current smokers ranged from 18 to 82 years in the intervention group $($ mean $=44.2 \pm 17.1)$ and $18-86$ years (mean $=42.4 \pm 20.6)$ in the control group. Most of the current smokers in the intervention and control group attended elementary and primary school (63\% and $51.9 \%)$ and almost all were employees $(77.8 \%$ and $63.0 \%)$. No significant difference between the two groups at baseline were identified ( $p>0.05)$ (Table 1).

\section{Negotiation for smoking ban inside the home}

Before program implementation, the intervention and control groups had no difference in the mean score of negotiation for a smoking ban inside the home ( $p>0.05)$. After program implementation, the mean score of negotiation for a smoking ban inside the homes of the intervention group was significantly higher than that at baseline and that of the control group $(\mathrm{p}<0.05)$ (Table 2$)$. The intervention and control groups had no difference in the mean score of emotional support for no-smoking inside home before program implementation ( $\mathrm{p}>0.05)$. After program implementation, the mean score of emotional support for no-smoking inside the home of the intervention group was significantly higher than that at baseline and that of the control group $(\mathrm{p}<0.05)$.

\section{Smoking-ban rules at home}

Before program implementation, there was no difference in establishing smoking-ban home rules between the intervention group and control groups ( $>>0.05)$. After program implementation, establishing smoking-ban home rules in the intervention group was significantly higher than that at baseline $(92.6 \%)$ and that of the control group $(18.5 \%)(\mathrm{p}<0.05)$ (Table 3$)$.

\section{Smoke-free home}

After six months, in the intervention group, 21 current

Table 1. Comparison of characteristic of family members and current smokers in the intervention group and the control group

\begin{tabular}{|c|c|c|c|c|c|c|}
\hline \multirow[t]{2}{*}{ Characteristics } & \multicolumn{2}{|c|}{$\begin{array}{l}\text { Intervention group } \\
\qquad(n=27)\end{array}$} & \multicolumn{2}{|c|}{$\begin{array}{l}\text { Control group } \\
(n=27)\end{array}$} & \multirow[t]{2}{*}{$x^{2}$} & \multirow[t]{2}{*}{$p$} \\
\hline & $n$ & $\%$ & $n$ & $\%$ & & \\
\hline Age of family members (years) & & & & & 0.948 & 0.000 \\
\hline $19-39$ & 8 & 29.6 & 7 & 25.9 & & \\
\hline $40-59$ & 9 & 33.4 & 9 & 33.4 & & \\
\hline$\geq 60$ & 10 & 37.0 & 11 & 40.7 & & \\
\hline Gender & & & & & -0.199 & 0.320 \\
\hline Male & 5 & 18.5 & 4 & 14.8 & & \\
\hline Female & 22 & 81.5 & 23 & 85.2 & & \\
\hline Relationship in family & & & & & 3.536 & 0.128 \\
\hline Harmony/unity & 25 & 92.6 & 17 & 63.0 & & \\
\hline Frequently/sometimes argue & 2 & 7.4 & 10 & 37.0 & & \\
\hline Age of smoker (years) & & & & & -0.073 & 0.717 \\
\hline $19-39$ & 10 & 37.0 & 12 & 44.4 & & \\
\hline $40-59$ & 12 & 44.5 & 9 & 33.4 & & \\
\hline$\geq 60$ & 5 & 18.5 & 6 & 22.2 & & \\
\hline Smoker's education level & & & & & -0.307 & 0.119 \\
\hline Less than elementary and primary school & 17 & 63.0 & 14 & 51.9 & & \\
\hline High school, college and higher & 10 & 37.0 & 13 & 48.1 & & \\
\hline Smoker's occupation & & & & & -0.141 & 0.484 \\
\hline Governed/business/ agriculturalist & 2 & 7.4 & 5 & 18.5 & & \\
\hline Employee & 21 & 77.8 & 17 & 63.0 & & \\
\hline Housewifery/student & 4 & 14.8 & 5 & 18.5 & & \\
\hline
\end{tabular}


Table 2. Comparison of family members negotiating for smoking ban inside home and emotional support for no-smoking inside home, between the intervention and control groups at baseline and after implementation

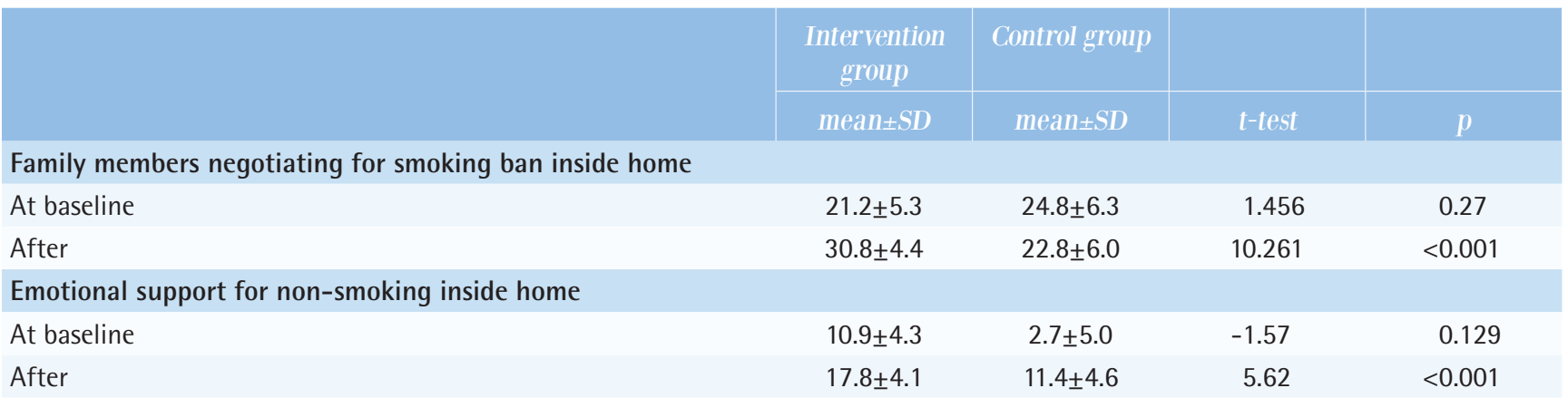

${ }^{*} \mathrm{p}<0.05$ significant.

Table 3. Control of smoking-ban rules between the intervention and control groups at the baseline and after implementation

\begin{tabular}{|c|c|c|c|c|c|c|}
\hline & \multicolumn{2}{|c|}{ Intervention group ( $n=27)$} & \multicolumn{2}{|c|}{ Control group ( $n=27)$} & \multirow[t]{2}{*}{$x^{2}$} & \multirow[t]{2}{*}{$p$} \\
\hline & $n$ & $\%$ & $n$ & $\%$ & & \\
\hline Smoking-ban rules (at baseline) & & & & & 0.13 & 1.000 \\
\hline Yes & 4 & 14.8 & 5 & 18.5 & & \\
\hline No & 23 & 85.2 & 22 & 81.5 & & \\
\hline Smoking-ban rules (after) & & & & & 30.00 & $<0.001$ \\
\hline Yes & 25 & 92.6 & 5 & 18.5 & & \\
\hline No & 2 & 7.4 & 22 & 81.5 & & \\
\hline
\end{tabular}

${ }^{*} \mathrm{p}<0.05$ significant.

Table 4. Control of smoke-free home between the intervention and control groups at the baseline and after implementation

\begin{tabular}{|c|c|c|c|c|}
\hline \multirow[t]{2}{*}{ Smoke-free home } & \multicolumn{2}{|c|}{ Intervention group (n=27) } & \multicolumn{2}{|c|}{ Control group ( $n=27)$} \\
\hline & $n$ & $\%$ & $n$ & $\%$ \\
\hline \multicolumn{5}{|c|}{ Smoke-free home (at baseline) } \\
\hline Yes & 0 & 0 & 0 & 0 \\
\hline No & 27 & 100.0 & 27 & 100.0 \\
\hline \multicolumn{5}{|c|}{ Smoke-free home (after) } \\
\hline Yes & 21 & 75.0 & 0 & 0 \\
\hline No & 6 & 25.0 & 27 & 100.0 \\
\hline
\end{tabular}

smokers began to smoke outside the home (75\%). While in the control group, none smoked outside the home $(0 \%)$. The number of smoke-free homes in the intervention group was higher than at baseline and that in the control group (Table 4).

\section{DISCUSSION}

The current results show that the community participation program constructed by a community committee and based on the concept of participation was effective in changing home environments, with the implementation of home smoking-ban rules by negotiation with the smokers at home.

Smokers' family members were able to express opinions by using soft words at the right time. Talking with smokers should be sincere and caring for their 
health while convincing them to see the dangers of SHS to family members living in the same home. Family members were allowed to share opinion and establish smoke-free home rules and also encouraged to avoid any possible conflicts. Smokers' families in suburban Thailand predominantly had a low level of education, and the majority were hired workers or housewives, which is consistent with previous studies reporting that smokers and their families have a low education level ${ }^{7,20,21}$. Previous research found that a factor associated with establishing smoke-free home rules was being a college graduate ${ }^{22}$. However, there was a good relationship in smokers' families and smokers without conflict. This contradicted earlier research indicating that allowing for smoking inside the home created conflict ${ }^{22}$.

Similarly, when parents share the idea about reducing secondhand smoke in home environments, the number of cigarettes smoked in the home decrease ${ }^{23}$. Successful negotiation depends heavily on the personalities of both those making the request and those they are making it to ${ }^{17,24}$. Our study is in line with previous research reporting that children with skills to negotiate with adults to convince them not to smoke inside the home will be able to achieve a smoke-free home ${ }^{25}$.

Moreover, posting no-smoking signs inside the home is important to remind family members, encourage smokers, and support a smoke-free environment at home. Previous research has noted that a 'No Smoking' sign may help prevent exposure to secondhand smoke at home and help enforce

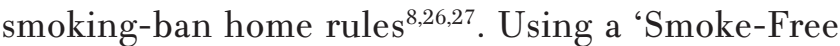
Home' sign functions as a visible positive force and notice for preventing smoking inside and has been found to be an effective strategy to increase voluntary smoke-free homes ${ }^{2,26,28}$.

With respect to emotional support for non-smoking inside the home, the community participation program for a smoke-free home can enhance emotional support for smokers to avoid smoking at home. The most effective social support is one unnoticed by the receiver and indicating a high level of emotional support to reduce smoking ${ }^{23,29}$. In contrast, there is an association between mood and smoking behavior, as smokers may increase their consumption of cigarettes when they feel happy or $\operatorname{sad}^{30}$. Thus, an attempt to quit smoking may fail due to the lack of assistance from their family ${ }^{31}$. Emotional support was associated with quitting smoking ${ }^{29,32}$.

The current study suggests that after the implementation of a community participation program for a smoke-free home, there was an increase in smoking-ban home rules which were established by family members and smokers, and about one-third of homes with smokers became smoke-free. This is in line with a previous study suggesting that only onethird of the participants reported having made their home smoke-free ${ }^{2,33}$. Therefore, establishing smokingban home rules requires collective agreement between family members and smokers to allow for participation and to create a smoke-free home environment. This is also similar to reports that smokers and nonsmokers viewed that smoking should not be allowed in homes ${ }^{2,34}$. Moreover, previous research has indicated that households within communities may be willing to create smoke-free home environments and support 'smoke-free home' management (restricting smoking in spaces indoors or on verandas) which may increase the number of smoke-free homes in the community ${ }^{21,30,35}$.

This research was a community participation program for smoke-free homes in a suburban community, Thailand. The success of the program was due to the good cooperation of the community committee, and various strategies implemented for a smoke-free home environment. The current study recommends that public health nurses should implement the 'Community Participation Program for Smoke-Free Homes' and work with the community committee as a partnership for increasing smokefree homes in their communities. The family is the key stakeholder who will support and make a rule in the house, so community committees should include smoke-free homes in the community agenda and support family members to achieve the goal.

\section{Limitations}

This study has several limitations. Our community may not be representative of other urban communities. There may have been a spillover between communities, and there may have been self-report bias.

\section{CONCLUSIONS}

This study showed that the community participation program for a smoke-free home effectively drives 
cooperation among family members and smokers to establish smoking-ban home rules and encourage smokers to smoke outdoors to manage a smokefree home environment. This will guide personnel in developing smoke-free homes through the participation of the community and every family member.

\section{REFERENCES}

1. Kaleta D, Polanska K, Usidame B. Smoke-Free Workplaces Are Associated with Protection from Second-Hand Smoke at Homes in Nigeria: Evidence for PopulationLevel Decisions. Biomed Res Int. 2015;2015:618640. doi:10.1155/2015/618640

2. St. Claire AW, Boyle RG, Schillo BA, Rode P, Taylor KA. Smokefree home rules adoption by smokers and nonsmokers: Minnesota, 1999-2010. Am J Prev Med. 2012;43(5 Suppl 3):S197-S204. doi:10.1016/j.amepre.2012.07.042

3. Lolley K, Marhé E, Seymour W, Lakhisaran J. Linking Global Youth Tobacco Survey (GYTS) data to tobacco control policy in Suriname. 2017;59 (Suppl 1):22-29. doi: $10.21149 / 7850$

4. Lee W, Hwang SH, Choi H, Kim H. The association between smoking or passive smoking and cardiovascular diseases using a Bayesian hierarchical model: based on the 2008-2013 Korea Community Health Survey. Epidemiol Health. 2017;39:e2017026. doi:10.4178/epih.e2017026

5. National Center for Chronic Disease Prevention and Health Promotion. [Best Practices for Comprehensive Tobacco Control Programs]. Article in Thai. National Center for Chronic Disease Prevention and Health Promotion Office; 2013.

6. Egbe CO, Petersen I, Meyer-Weitz A. Community Participation in Tobacco Control in a Nigerian Setting. J Psychol Afr. 2013;23(2):311-315. doi:10.1080/14330237.2013.10820628

7. Kruger J, Jama A, Homa DM, Babb SD, King BA. Smoke-free home and vehicle rules by tobacco use status among US adults. Prev Med. 2015;78:9-13. doi:10.1016/j.ypmed.2015.06.004

8. Zamani A, Golshiri P, Moqtader B. The Study Protocol of Women's Education to Create Smoke-free Home on the Basis of Family Ties in Isfahan, Iran. Int J Prev Med. 2013;4(11):1312-1317. Accessed September 21, 2020. https://www.ncbi.nlm.nih.gov/pmc/articles/ PMC3883257/

9. Boonserm C, Suthitiwanich P, Worrasa R. Smoking behaviors among youth in Chaiyaphum Province. Article in Thai. Journal of Health Science. 2009;3(2):6-14.

10. Taniguchi G, Tanaka H, Saka H, et al. Cognitive, behavioural and psychosocial factors associated with successful and maintained quit smoking status among patients who received smoking cessation intervention with nurses' counselling. J Adv Nurs. 2017;73(7):16811695. doi:10.1111/jan.13258
11. Kale D, Gilbert HM, Sutton S. Are predictors of making a quit attempt the same as predictors of 3-month abstinence from smoking? Findings from a sample of smokers recruited for a study of computer-tailored smoking cessation advice in primary care. Addiction. 2015;110(10):1653-1664. doi:10.1111/add.12972

12. Smoking at home to be banned. Bangkok Post. June 21, 2019. Accessed October 25, 2020. https://www. bangkokpost.com/thailand/general/1699504/smokingat-home-to-be-banned

13. Nicholson JS, McDermott MJ, Huang Q, Zhang H, Tyc VL. Full and Home Smoking Ban Adoption After a Randomized Controlled Trial Targeting Secondhand Smoke Exposure Reduction. Nicotine Tob Res. 2015;17(5):612-616. doi:10.1093/ntr/ntu201

14. Zhang $X$. The association between indoor smoke-free home rules and the use of cigar and smokeless tobacco: A longitudinal study. Addict Behav. 2017;74:153-155. doi:10.1016/j.addbeh.2017.06.013

15. Kaleta D, Fronczak A, Usidame B, et al. Implementation of smoke-free homes in Poland. Int J Occup Med Environ Health. 2016;29(1):137-148. doi:10.13075/ijomeh.1896.00435

16. Cattaruzza MS. Tobacco-free homes for tobacco-free generations: establishing positive smoke-free role models for youth. Rev Port Pneumol. 2015;21(4):173-174. doi:10.1016/j.rppnen.2015.06.005

17. McRae B. Negotiating and Influencing Skills: The Art of Creating and Claiming Value. Sage Publications; 1998.

18. Thai Ministry of Public Health. Tobacco Control Plan B.E.2560-B.E.2564. In Thai. National Center for Chronic Disease Prevention and Health Promotion; 2017. Accesed May, 2017. https://ddc.moph.go.th/

19. Thanyaburi Health District Office. Number of Chronic Respiratory Disease, Coronary Heart Disease, Lung Carcinoma, and Stroke Report B.E. 2559. Report in Thai. 2016.

20. Hamadeh RR, Ahmed J, Al Kawari M, Bucheeri S. Smoking behavior of males attending the quit tobacco clinics in Bahrain and their knowledge on tobacco smoking health hazards. BMC Public Health. 2018;18:19. doi:10.1186/s12889-018-5104-7

21. Mittal S, Das S. Toward smoke-free homes: A community-based study on initiatives of rural Indian women. J Family Community Med. 2011;18(2):69-73. doi:10.4103/2230-8229.83371

22. Berg CJ, Daley CM, Nazir N, et al. Smoke-Free Policies in the Workplace and in the Home among American Indians. J Health Dispar Res Pract. 2012;5(2):81-91. Accessed September 21, 2020. https://www.ncbi.nlm.nih.gov/ pmc/articles/PMC3689312/

23. Herbert RJ, Gagnon AJ, O'Loughlin JL, Rennick JE. Testing an empowerment intervention to help parents make homes smoke-free: a randomised controlled trial. J Community Health. 2011;36(4):650-657. 
doi:10.1007/s10900-011-9356-8

24. Robinson J, Ritchie D, Amos A, Greaves L, CunninghamBurley S. Volunteered, negotiated, enforced: family politics and the regulation of home smoking. Sociol Health Illn. 2011;33(1):66-80. doi:10.1111/j.1467-9566.2010.01273.x

25. Siddiqi K, Huque R, Jackson C, et al. Children Learning About Secondhand Smoke (CLASS II): protocol of a pilot cluster randomised controlled trial. BMJ Open. 2015;5(8). doi:10.1136/bmjopen-2015-008749

26. Escoffery C, Mullen P, Genkin B, et al. Coaching to create a smoke-free home in a brief second-hand smoke intervention. Health Educ Res. 2017;32(6):555-568. doi:10.1093/her/cyx072

27. Zhang X, Martinez-Donate AP, Kuo D, Piper M. Beyond cigarette smoking: smoke-free home rules and use of alternative tobacco products. Perspect Public Health. 2016;136(1):30-33. doi:10.1177/1757913915600194

28. Lee S, Tsai YW, Sung HY. Smoking cessation and receipt of cessation advice from health professionals among older smokers in Taiwan. Prev Med. 2016;91:89-95. doi:10.1016/j.ypmed.2016.08.002

29. Lüscher J, Stadler G, Ochsner S, et al. Daily negative affect and smoking after a self-set quit attempt: The role of dyadic invisible social support in a daily diary study. Br J Health Psychol. 2015;20(4):708-723. doi:10.1111/bjhp.12135

30. Pavlović M, Zezelj I. Not Only When Feeling Down: The Relationship Between Mood Intensity and Smoking Behavior. Subst Use Misuse. 2017;52(4):488-492. doi:10.1080/10826084.2016.1245334

31. Phillips A, Monaem A, Newman C. A qualitative study of smoking within a Western Sydney Arabic-speaking community: a focus on men in the context of their families. Health Promot J Austr. 2015;26(1):10-15. doi:10.1071/HE14030

32. Ochsner S, Knoll N, Stadler G, Luszczynska A, Hornung R, Scholz U. Interacting Effects of Receiving Social Control and Social Support During Smoking Cessation. Ann Behav Med. 2015;49(1):141-146. doi:10.1007/s12160-014-9635-6

33. Kegler MC, Escoffery C, Bundy L, et al. Pilot Study Results from a Brief Intervention to Create SmokeFree Homes. J Environ Public Health. 2012:2012:1-9. doi:10.1155/2012/951426

34. Ballor DL, Henson H, MacGuire K. Support for NoSmoking Policies Among Residents of Public Multiunit Housing Differs by Smoking Status. J Community Health. 2013;38(6):1074-1080. doi:10.1007/s10900-013-9716-7

35. Clough AR, Grant K, Robertson J, Wrigley M, Nichols N, Fitzgibbon T. Interventions to encourage smoke-free homes in remote indigenous Australian communities: a study protocol to evaluate the effects of a community-inspired awareness-raising and motivational enhancement strategy. BMJ Open. 2018;8(3). doi:10.1136/bmjopen-2017-018955

\section{ACKNOWLEDGEMENTS}

We thank both groups of participants, the sub-district and village headmen, the community committee, health volunteers, and professional registered nurses, Fah-Sai Clinic, Thanyaburi Hospital, the Director of Lum Puk Gut Sub-District Health Promotion Hospital, health officers, public health technical officers, and the Action on Smoking and Health Foundation of Thailand.

\section{CONFLICTS OF INTEREST}

The authors have each completed and submitted an ICMJE form for disclosure of potential conflicts of interest. The authors declare that they have no competing interests, financial or otherwise, related to the current work. P. Suteerangkul, S. Kalampakorn and N. Auemaneekul report that Tobacco Control Research and Knowledge Management Center (TRC) provided partial support for the implementation of the smoke-free home program, the National Research Council of Thailand (NRCT) provided partial support for program implementation and publication of the research, and the Faculty of Public Health, Mahidol University provided partial support for the publication. S. Lagampan reports Tobacco Control Research and Knowledge Management Center (TRC) support for the smoke-free home program and partial support for publication of the research. Furthermore, the National Research Council of Thailand (NRCT) supported program implementation and the Faculty of Public Health of Mahidol University partially supported the publication of the research.

\section{FUNDING}

This work was supported by the National Research Council of Thailand (NRCT), Tobacco Control Research and Knowledge Management Center (TRC), and Public Health Nursing Department, Faculty of Public Health, Mahidol University.

\section{ETHICAL APPROVAL AND INFORMED CONSENT}

This research was approved by the Ethical Review Committee for Human Research, Faculty of Public Health, Mahidol University (COA. No. MUPH 2016-114). Clarification was made to the participants about their participation and they were asked to sign a consent form to voluntarily participate in the program. Participants were free to withdraw from the program at any time.

\section{PROVENANCE AND PEER REVIEW}

Not commissioned; externally peer reviewed. 